\title{
Reconfigurable Two-Current Source Supplied Signal Conditioner for Resistive Sensors
}

\author{
Wojciech Walendziuk ${ }^{1}$, Adam Idzkowski ${ }^{1}$, Jerzy Golebiowski ${ }^{1}$ \\ ${ }^{1}$ Department of Electrical Engineering, Bialystok University of Technology, \\ Wiejska 45D St., 15-351 Bialystok, Poland \\ w.walendziuk@pb.edu.pl
}

\begin{abstract}
The principle of operation, its practical realization and measurement research of a reconfigured system of a signal conditioner are presented. A two-sourced conditioner supplied by direct current with four resistance sensors and four switching keys was experimentally tested. In the example application the resistance of sensors in the function of the same point load, caused by perpendicular force, was measured. In order to compare the results achieved with the use of a conditioning circuit, similar tests were carried out for a four-channel Wheatstone's bridge-based commercial acquisition card. The research aimed at confirming the possibility of implementing the constructed signal conditioner in cheap measurement equipment.
\end{abstract}

Index Terms-Measurement techniques; sensor systems; error analysis.

\section{INTRODUCTION}

Commonly known signal conditioners of resistance sensors are based on bridge systems [1] or Anderson's current loop [2]. Systems built on the basis of a nonbalanced Wheatstone's bridge, supplied by direct or alternating current sources, enable measuring only one input quantity, i.e. resistance change of e.g. a strain gauge or a resistance temperature detector (RTD). For this reason, multichannel systems, multiplying single bridges, are created to measure many quantities simultaneously [3].

The authors of this paper presented the issue of realizing a two-current supplied circuit in their previous works [4]. The resistance elements in the circuit were connected into a fourarm, inseparable bridge. Two current sources of identical parameters were attached to the opposite nodes of the system, two additional reference resistors - to the other nodes. A circuit of this type enables measuring the change of resistance values of the sensors through appropriate records of the voltage drop on the opposite nodes of the bridge system. Due to this phenomenon, with the help of appropriate mathematical formulas, it was possible to determine the two searched physical quantities (e.g. strain and temperature change) in the same point of the cantilever beam. The circuit, however, has a disadvantage. It gives simple linear dependences of output voltages in the function of input quantities only for small resistance increases of the sensors.

Manuscript received 29 November, 2015; accepted 24 March, 2016.

The paper was prepared at Bialystok University of Technology within a framework of the S/WE/1/2013 project funded by Ministry of Science and Higher Education.
This article contains a description, the principle of operation and measurement properties of an original, reconfigurable version of a conditioner. A prototype of a circuit is also presented. Its metrological properties were also examined. Moreover, a comparative analysis of the parameters of the prototype and the commercial product, NI USB-9237 [5], equipped with a 24-bit Delta-Sigma conversion and the Wheatstone's bridge based measurement channels, was carried out. The research was aimed at confirming the possibility of applying the constructed conditioner in the measurement equipment.

\section{CONSTRUCtion AND THE PRINCIPLE OF OPERATION OF A RECONFIGURABLE CONDITIONING CIRCUIT}

The conditioning circuit (Fig. 1), presented here, is more functional than a two-current system of a four-armed inseparable bridge. The possibility of the circuit reconfiguration enables measurement of combination of even four resistance increases. It is an original solution, comparing with other commonly known conditioners [1], [6].

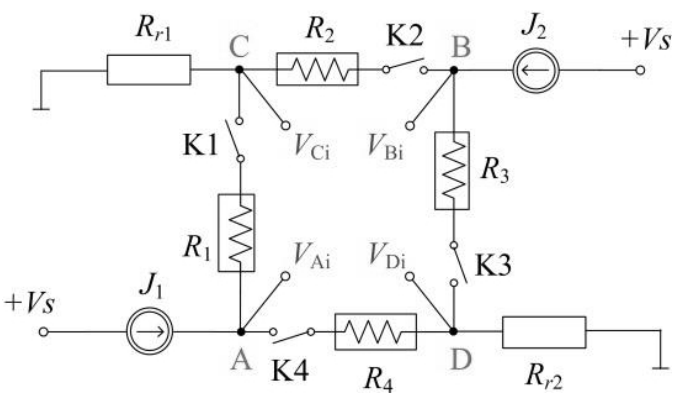

Fig. 1. Schematic diagram of a circuit with two current sources, four sensors and four switching keys.

The reconfigurable conditioning circuit $(2 \mathrm{~J}+2 \mathrm{R}+4 \mathrm{~K})$ consists of resistance sensors connected into a bridge circuit, two precise reference resistors, two current sources and four switching keys which change the circuit way of operating. The measurement done with the use of such conditioner concerns examining the resistance increases of the bridge nodes $\Delta R_{1}, \Delta R_{2}, \Delta R_{3}, \Delta R_{4}$, which are proportional to the changes of the measured quantities. Next, the potential values in $\mathrm{A}, \mathrm{B}, \mathrm{C}$ and $\mathrm{D}$ nodes, recorded e.g. in a measurement data acquisition program, are adequately converted in order to determine the searched physical quantities measured with resistance sensors. It is worth stressing that the measurement process is carried out in a sequence of cycles controlled by the keys K1, K2, K3 and K4. 


\section{A. Cyclical Work of a Circuit with One Switched-On Key}

As it is easily observable (Fig. 2), the circuit can be reconfigured in pairs into the form of systems resembling a so called Anderson's current loop [6]. Such action enables conducting a preliminary calibration of the circuit on the basis of appropriate measurements of voltage drop on the reference resistor and on the measurement sensor, and then switching into further work mode of the circuit.

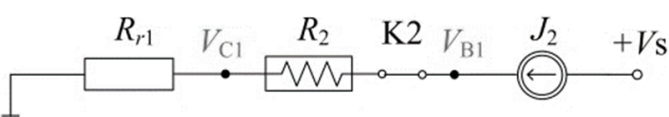

Fig. 2. Example configuration (measurement cycle 20) with only one key $\mathrm{K} 2$ switched on and other keys - K1, K3, K4 - switched off.

First four measurement cycles (named 10, 20, 30 and 40), with only one key is switched on, aim at computing initial resistances of the $R_{10}, R_{20}, R_{30}$ and $R_{40}$ sensors, according to the dependences given in Table I.

TABLE I. DETERMINING INITIAL RESISTANCES OF $R_{I 0}$ SENSORS.

\begin{tabular}{|c|c|c|c|c|c|}
\hline \multirow{2}{*}{ Cycle } & \multicolumn{3}{|c|}{$\begin{array}{c}\text { Logical state of the } \\
\text { keys }\end{array}$} & \multicolumn{1}{c|}{$\begin{array}{c}\text { Calculated initial resistances of } \\
\text { the sensors }\end{array}$} \\
\cline { 2 - 6 } & $\mathbf{K 1}$ & $\mathbf{K 2}$ & $\mathbf{K 3}$ & $\mathbf{K 4}$ & \\
\hline $\mathbf{1 0}$ & 1 & 0 & 0 & 0 & $R_{10}=\frac{V_{\mathrm{A} 10}-V_{\mathrm{C} 10}}{J_{1}}-R_{\mathrm{K} 1}$ \\
\hline $\mathbf{2 0}$ & 0 & 1 & 0 & 0 & $R_{20}=\frac{V_{\mathrm{B} 20}-V_{\mathrm{C} 20}}{J_{2}}-R_{\mathrm{K} 2}$ \\
\hline $\mathbf{3 0}$ & 0 & 0 & 1 & 0 & $R_{30}=\frac{V_{\mathrm{B} 30}-V_{\mathrm{D} 30}}{J_{2}}-R_{\mathrm{K} 3}$ \\
\hline $\mathbf{4 0}$ & 0 & 0 & 0 & 1 & $R_{40}=\frac{V_{\mathrm{A} 40}-V_{\mathrm{D} 40}}{J_{1}}-R_{\mathrm{K} 4}$ \\
\hline
\end{tabular}

where: $V_{\mathrm{A} 10}, V_{\mathrm{C} 10}, V_{\mathrm{B} 20}, V_{\mathrm{C} 20}, V_{\mathrm{B} 30}, V_{\mathrm{D} 30}, V_{\mathrm{A} 40}, V_{\mathrm{D} 40}-$ measured potentials in A, B, C and D nodes in 10, 20, 30 and 40 cycles, $R_{\mathrm{K} i}-$ resistance of the $(i=1,2,3,4)$ key.

The presented dependences (Table I) prove that calculating initial resistances $R_{i 0}$ require the resistance values of the $R_{\mathrm{K} i}$ keys. An important advantage of the circuit is the fact that, at complete configuration of the bridge and as a result of mathematical operations conducted in a sequence of cycles, the resistances can vary and they do not influence the acquired measurement results.

\section{B. Cyclical Work of a Circuit with Two Keys Switched-On and Two Keys Switched-Off}

Two keys switched on and two - switched off - is another configuration of the circuit (Fig. 3). Four measurement cycles, named 1, 2, 3 and 4, can be distinguished here. In these cycles, the potential values in points A, B, C and D are respectively subtracted or added in numerical operations, e.g. in a measurement system controlled by a PC. Formulating sum and subtraction equations of two increases for cycle no. 1 is given as an example. The process is analogical for other cycles. It is worth stressing that all voltage measurement operations in $V_{\mathrm{A} 1}, V_{\mathrm{B} 1}, V_{\mathrm{C} 1}, V_{\mathrm{D} 1}$ nodes are conducted in relation to the same analog ground.

The potential difference between $\mathrm{A} 1$ and $\mathrm{B} 1$ nodes in cycle no. 1 (Fig. 3 ) equals

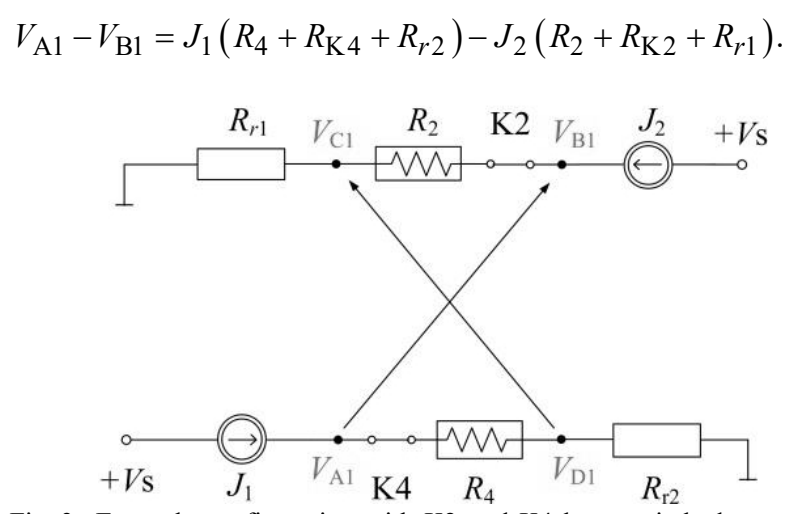

Fig. 3. Example configuration with $\mathrm{K} 2$ and $\mathrm{K} 4$ keys switched on and $\mathrm{K} 1$ and K3 keys switched off.

If we assume that the currents of the sources differ of $\Delta J$, and the sensors resistances are the sum of their initial values and resistance increases $\left(J_{2}=J_{1}+\Delta J, \quad R_{2}=R_{20}+\Delta R_{2}\right.$, $\left.R_{4}=R_{40}+\Delta R_{4}\right)$, then the subtraction of resistance increases $R_{4}$ and $R_{2}$ after conversions equals

$$
\begin{gathered}
\Delta R_{4}-\left(1+\frac{\Delta J}{J_{1}}\right) \Delta R_{2}=\frac{V_{\mathrm{A} 1}-V_{\mathrm{B} 1}}{J_{1}}+\frac{V_{\mathrm{B} 20}-V_{\mathrm{C} 20}}{J_{1}+\Delta J}- \\
-\frac{V_{\mathrm{A} 40}-V_{\mathrm{D} 40}}{J_{1}}+\left(R_{r 1}-R_{r 2}\right)+\frac{\Delta J}{J_{1}}\left(\frac{V_{\mathrm{B} 20}-V_{\mathrm{C} 20}}{J_{1}+\Delta J}+R_{r 1}\right) .
\end{gathered}
$$

In (2), it was assumed on the basis of Table I that the subtraction of the initial resistances in cycles 20 and 40 equals

$R_{20}-R_{40}=\frac{V_{\mathrm{B} 20}-V_{\mathrm{C} 20}}{J_{1}+\Delta J}-\frac{V_{\mathrm{A} 40}-V_{\mathrm{D} 40}}{J_{1}}+\left(R_{\mathrm{K} 4}-R_{\mathrm{K} 2}\right)$.

As it can be seen in (2), the influence of current subtraction $\Delta J$ is significant, whereas, the resistances of the keys were reduced. Assuming that $\Delta J=0, J_{1}=J$ and because of the fact that reference resistances are measured as voltage drops at direct flowing current $J$, their subtraction equals

$$
R_{r 1}-R_{r 2}=\frac{V_{\mathrm{C} 1}-V_{\mathrm{D} 1}}{J}
$$

Assuming (4) in (2), the following simplified equation was obtained

$$
\begin{gathered}
\Delta R_{4}-\Delta R_{2}=\frac{\left(V_{\mathrm{A} 1}-V_{\mathrm{B} 1}+V_{\mathrm{C} 1}-V_{\mathrm{D} 1}\right)}{J}- \\
-\frac{\left(V_{\mathrm{A} 40}-V_{\mathrm{B} 20}+V_{\mathrm{C} 20}-V_{\mathrm{D} 40}\right)}{J} .
\end{gathered}
$$

Similarly to (5), the potential sum in A1 and B1 nodes and the resistance increases sum of $R_{4}$ and $R_{2}$ can be calculated

$$
\begin{gathered}
\Delta R_{4}+\left(1+\frac{\Delta J}{J_{1}}\right) \Delta R_{2}=\frac{V_{\mathrm{A} 1}+V_{\mathrm{B} 1}}{J_{1}}-\frac{V_{\mathrm{B} 20}-V_{\mathrm{C} 20}}{J_{1}+\Delta J}- \\
-\frac{V_{\mathrm{A} 40}-V_{\mathrm{D} 40}}{J_{1}}-\left(R_{r 1}+R_{r 2}\right)-\frac{\Delta J}{J_{1}}\left(\frac{V_{\mathrm{B} 20}-V_{\mathrm{C} 20}}{J_{1}+\Delta J}+R_{r 1}\right) .
\end{gathered}
$$


Assuming that $\Delta J=0$ and $J_{1}=J$, it equals

$$
\begin{gathered}
\Delta R_{4}+\Delta R_{2}=\frac{\left(V_{\mathrm{A} 1}+V_{\mathrm{B} 1}-V_{\mathrm{C} 1}-V_{\mathrm{D} 1}\right)}{J}- \\
-\frac{\left(V_{\mathrm{A} 40}+V_{\mathrm{B} 20}-V_{\mathrm{C} 20}-V_{\mathrm{D} 40}\right)}{J} .
\end{gathered}
$$

Table II below contains simplified formulas (at $\Delta J=0$,

\begin{tabular}{|c|c|c|c|c|c|}
\hline Cycle & K1 & K2 & K3 & K4 & $\begin{array}{l}\text { Calculated subtractions and sums of the } \\
\text { resistance increases }\end{array}$ \\
\hline 1 & 0 & 1 & 0 & 1 & $\begin{array}{c}\Delta R_{4}-\Delta R_{2}=\frac{\left(V_{\mathrm{A} 1}-V_{\mathrm{B} 1}+V_{\mathrm{C} 1}-V_{\mathrm{D} 1}\right)}{J}- \\
-\frac{\left(V_{\mathrm{A} 40}-V_{\mathrm{B} 20}+V_{\mathrm{C} 20}-V_{\mathrm{D} 40}\right)}{J} \\
\Delta R_{4}+\Delta R_{2}=\frac{\left(V_{\mathrm{A} 1}+V_{\mathrm{B} 1}-V_{\mathrm{C} 1}-V_{\mathrm{D} 1}\right)}{J}- \\
-\frac{\left(V_{\mathrm{A} 40}+V_{\mathrm{B} 20}-V_{\mathrm{C} 20}-V_{\mathrm{D} 40}\right)}{J}\end{array}$ \\
\hline 2 & 1 & 0 & 1 & 0 & $\begin{array}{c}\Delta R_{1}-\Delta R_{3}=\frac{\left(V_{\mathrm{A} 2}-V_{\mathrm{B} 2}-V_{\mathrm{C} 2}+V_{\mathrm{D} 2}\right)}{J}- \\
-\frac{\left(V_{\mathrm{A} 10}-V_{\mathrm{B} 30}-V_{\mathrm{C} 10}+V_{\mathrm{D} 30}\right)}{J} \\
\Delta R_{1}+\Delta R_{3}=\frac{\left(V_{\mathrm{A} 2}+V_{\mathrm{B} 2}-V_{\mathrm{C} 2}-V_{\mathrm{D} 2}\right)}{J}- \\
-\frac{\left(V_{\mathrm{A} 10}+V_{\mathrm{B} 30}-V_{\mathrm{C} 10}-V_{\mathrm{D} 30}\right)}{J}\end{array}$ \\
\hline 3 & 1 & 1 & 0 & 0 & $\begin{array}{c}\Delta R_{1}-\Delta R_{2}= \\
=\frac{\left(V_{\mathrm{A} 3}-V_{\mathrm{B} 3}\right)-\left(V_{\mathrm{A} 10}-V_{\mathrm{C} 10}-V_{\mathrm{B} 20}+V_{\mathrm{C} 20}\right)}{J} \\
\Delta R_{1}+\Delta R_{2}= \\
=\frac{\left(V_{\mathrm{A} 3}+V_{\mathrm{B} 3}\right)-\left(V_{\mathrm{A} 10}-V_{\mathrm{C} 10}+V_{\mathrm{B} 20}-V_{\mathrm{C} 20}\right)}{J}\end{array}$ \\
\hline 4 & 0 & 0 & 1 & 1 & $\begin{array}{c}\Delta R_{4}-\Delta R_{3}= \\
=\frac{\left(V_{\mathrm{A} 4}-V_{\mathrm{B} 4}\right)-\left(V_{\mathrm{A} 40}-V_{\mathrm{D} 40}-V_{\mathrm{B} 30}+V_{\mathrm{D} 30}\right)}{J} \\
\Delta R_{4}+\Delta R_{3}= \\
=\frac{\left(V_{\mathrm{A} 4}+V_{\mathrm{B} 4}\right)-\left(V_{\mathrm{A} 40}-V_{\mathrm{D} 40}+V_{\mathrm{B} 30}-V_{\mathrm{D} 30}\right)}{J}\end{array}$ \\
\hline
\end{tabular}
$J_{1}=J$ ) for all measurement cycles.

The analysed method of potential values measurement in four points with a quick keys switching enables the measurement of four combinations of subtractions and sums of $R_{1}, R_{2}, R_{3}, R_{4}$ sensors resistance increases in respective nodes of the circuit. Conducting further arithmetical operations (summing and subtracting), equations describing one, two, three or four resistance increases in respective nodes of the circuit (among the nodes A, B, C and D) can be obtained. Resistances of the connecting wires sum up, similarly as the keys resistances.

Table III contains equations for particular resistance increases determined on the basis of pairs of equations given in Table II.

As it can be observed in Table III, four resistance increases of the $\Delta R_{i}$ sensors can be given for two optional variants of the circuit operation (i.e. in cycles no. 10, 20, 30, 40, 1, 2 or $10,20,30,40,3,4)$.

TABLE III. DETERMINING RESISTANCE INCREASES OF THE SENSORS FOR $\triangle J=0$.

\begin{tabular}{|c|c|c|c|c|c}
\hline Cycle & $\mathbf{K 1}$ & $\mathbf{K 2}$ & $\mathbf{K 3}$ & $\mathbf{K 4}$ & Calculated resistance increases \\
\hline 1 & 0 & 1 & 0 & 1 & $\Delta R_{2}=\frac{\left(V_{\mathrm{B} 1}-V_{\mathrm{C} 1}\right)-\left(V_{\mathrm{B} 20}-V_{\mathrm{C} 20}\right)}{J}$ \\
\hline 2 & 1 & 0 & 1 & 0 & $\Delta R_{4}=\frac{\left(V_{\mathrm{A} 1}-V_{\mathrm{D} 1}\right)-\left(V_{\mathrm{A} 40}-V_{\mathrm{D} 40}\right)}{J}$ \\
\hline 3 & 1 & 1 & 0 & 0 & $\Delta R_{1}=\frac{\left(V_{\mathrm{A} 2}-V_{\mathrm{C} 2}\right)-\left(V_{\mathrm{A} 10}-V_{\mathrm{C} 10}\right)}{J}$ \\
\hline 4 & 0 & 0 & 1 & 1 & $\Delta R_{3}=\frac{\left(V_{\mathrm{B} 2}-V_{\mathrm{D} 2}\right)-\left(V_{\mathrm{B} 30}-V_{\mathrm{D} 30}\right)}{J}$ \\
\hline & & & & & \\
\hline
\end{tabular}

Cycles no. 20, 20, 30 and 40 are used to calibrate the zero of the circuit, which causes that the differences of the sensors initial resistances and the resistances of their leads, occurring in reality, do not influence the obtained measurement results. Moreover, sensors of various kinds may be attached to this circuit (e.g. strain gauges or RTD sensors). It can also be observed that in cycles 1 and 2, unlike cycles 3 and 4 , the components of the sum or the subtraction of reference resistance $R_{r 1}$ and $R_{r 2}$ occur.

It is vital to keep the value of the $\Delta J / J_{1}$ quotient on the possibly smallest level. Then, the equations from Table II and Table III can be assumed as reliable.

\section{REALIZATION AND LABORATORY EXPERIMENT CONDUCTED ON THE WORKED-OUT RECONFIGURABLE CIRCUIT}

\section{A. Realization of the Reconfigurable Circuit}

The prototype of the configurable circuit (Fig. 4(a), Fig. 4(b)) was realized with the use of an NI USB-6215 multifunction measurement card [7]. The card is equipped with a 16-bit $\mathrm{A} / \mathrm{C}$ converter with the sampling speed of $250 \mathrm{kS} / \mathrm{s}, 16$ analog voltage inputs of $-10 \mathrm{~V}$ to $10 \mathrm{~V}, 4$ digital inputs, 4 digital outputs and 2 analog voltage outputs. In order to measure the $V_{\mathrm{A}}, V_{\mathrm{B}}, V_{\mathrm{C}}, V_{\mathrm{D}}$ potentials, 4 analog inputs (AI1, AI2, AI3, AI4) of $0 \mathrm{~V}$ to $5 \mathrm{~V}$ were used.

Additionally, two differential analog inputs (AI1-AI1_2 and AI3-AI2_2) of $0 \mathrm{~V}$ to $5 \mathrm{~V}$ were used to conduct measurements of $J_{1}$ and $J_{2}$ currents of the LT3092 sources. The controlling process of four keys of the DG2042 integrated circuit (SW1, SW2, SW3, SW4) was completed 
with the use of digital outputs.

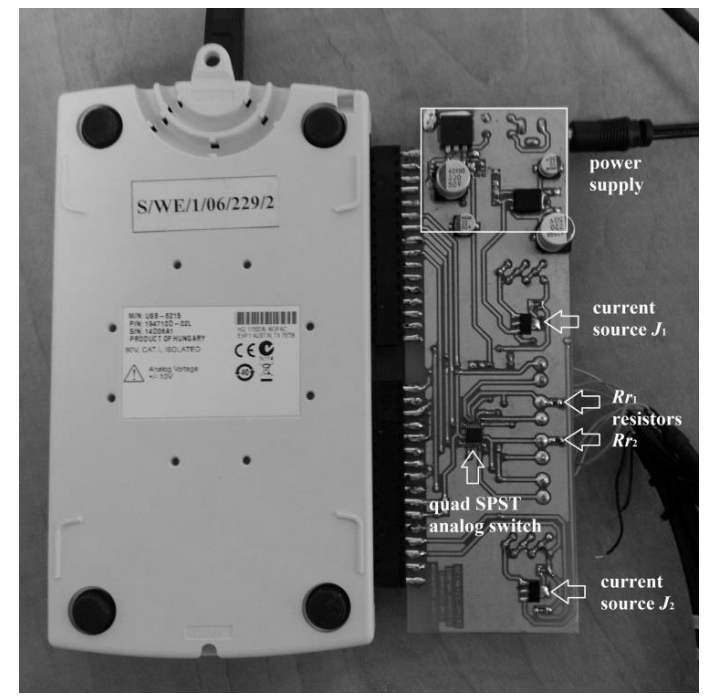

a)

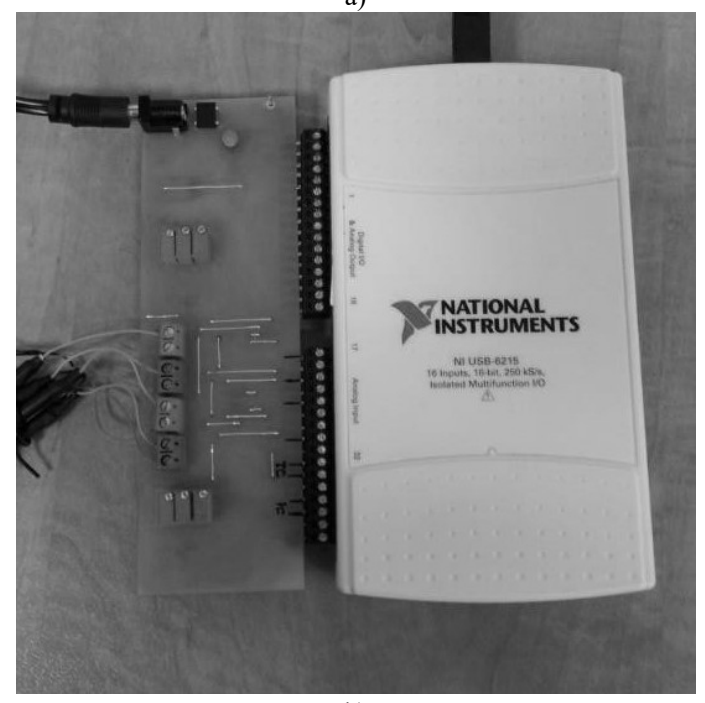

b)

Fig. 4. The bottom view of the reconfigurable $2 J+2 R+4 K$ PCB board with visible quad SPST analog switch, two programmable two-terminal current sources and power supply circuit (a); the top view of the reconfigurable $2 \mathrm{~J}+2 \mathrm{R}+4 \mathrm{~K}$ PCB board connected to an NI USB-6215 acquisition card (b).

Occurring problems with computation resulting in a transient state during switching the LT3092 source is described in [8]. The current sources are not regulated. An ADC Delta-Sigma modulator, which significantly enhances metrological properties of the circuit, was not applied here, either [9].

\section{B. Laboratory Tests}

The aim of the laboratory tests of the worked out prototype conditioner built of cheap components was to evaluate its utility in relation to a commercial product (treated as reference).

This was completed through determining static characteristics of the resistance increases of four sensors in the power function. A one-sidedly attached cantilever beam with a power meter placed on its end was used as a power model [10].

A measurement stand was built in order to test four sensors simultaneously (Fig. 5). The sensors were attached to four measurement channels (in a half-bridge configuration) of the NI 9237 strain gauge system of the 24-bit resolution. As it can be seen in Fig. 6, an additional CL17z transducer was situated among the power sensors (A, $\mathrm{B}, \mathrm{C}, \mathrm{D})$ [11]. The transducer was attached to the CL363 meter which was calibrated with it.

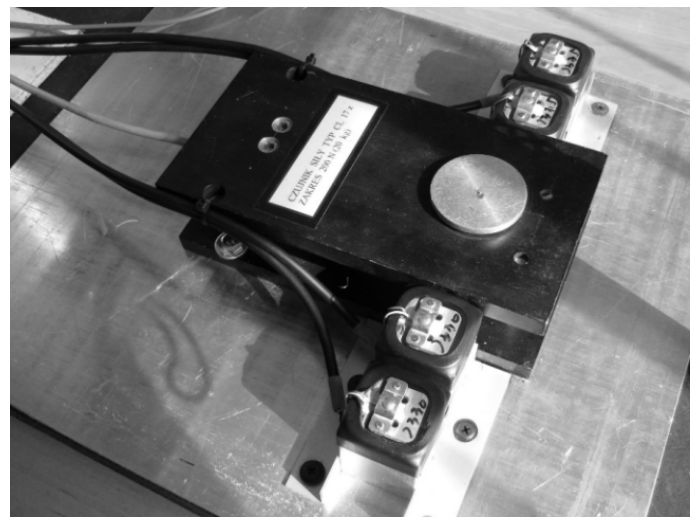

Fig. 5. Four strain gauge force sensors and a precise CL17z sensor (in the middle).

Force $F$ was enhanced by the jackscrews mechanism and measured with a CL363 meter. Its value was between $0 \mathrm{~N}$ and $100 \mathrm{~N}$ (with a $10 \mathrm{~N}$ step).

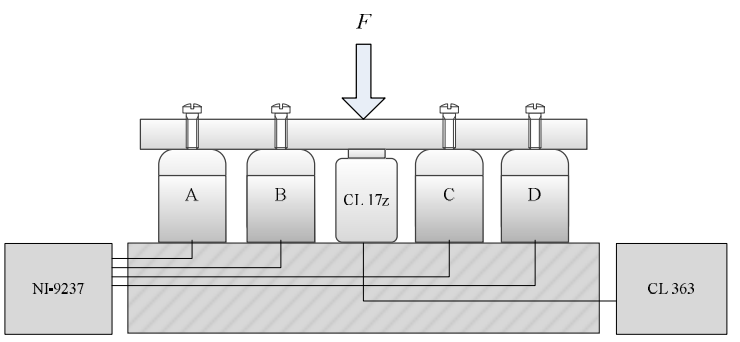

Fig. 6. Scheme of laboratory stand for measuring static characteristics of force transducers $(F$ - pressure on a bar, A, B, C, D - force sensors, CL17z - a model force transducer, NI 9237 - a strain gauge bridge by National Instruments, CL363 - a force sensor calibrated with CL17z).

The measurement range of the $\mathrm{CL} 17 \mathrm{z}$ force transducer is up to $200 \mathrm{~N}$. The information provided by the manufacturer says that the boundary measurement error of pressure equals $\pm 0.1 \mathrm{~N}$.

The cantilever beams of force sensors were pressed with the use of four screws implemented in the bar of the square diameter (Fig. 5). Regulations of the screws before the measurement give the possibility to correct the differences in geometry (the level of attachment). Because of this fact all beams of sensors can be pressed at the same time. Consequently, resistance increases of the sensors for $F=0$ equal $0\left(\Delta R_{i}=0\right.$, where $\left.i=1,2,3,4\right)$, and for $F>0-$ the increases are greater than $0\left(\Delta R_{i}>0\right)$.

Resistance increases $\Delta R_{i}$ (where $i=1,2,3,4$ ) for four strain gauge transducers, pressed by the force $F$, were measured with the use of an NI 9237 bridge.

The force was measured with the use of a set of a CL17z transducer and a CL363 meter. The limiting error for the measured resistance increase of $2 \Omega$ equalled $\pm 0.005 \Omega$. The mentioned value was determined on the basis of the formula given by the manufacturer of the device [10].

The same test was conducted for the reconfigurable circuit. The results presented in the further part of the article were obtained at equal current sources $J_{1}=J_{2}=2.33 \mathrm{~mA}$, $10 \mathrm{~Hz}$ keys switching frequency, and standard arithmetic approximation of 500 samples. 


\section{Research Results}

Linear models of resistance increases for four strain gauges in the force function were determined on the basis of the measurement results done with the use of an NI 9237 bridge (a commercial product) and a reconfigurable circuit $2 \mathrm{~J}+2 \mathrm{R}+4 \mathrm{~K}$ (a self-constructed prototype).

TABLE IV. THEORETICAL MODELS FOR THE REFERENCE MODEL (NI 9237), DESCRIBING RESISTANCE INCREASES OF THE SENSORS IN THE FORCE FUNCTION AND THEIR PARAMETERS.

\begin{tabular}{|c|c|c|c|c|}
\hline & Sensor $\boldsymbol{R}_{\mathbf{1}}$ & Sensor $\boldsymbol{R}_{\mathbf{2}}$ & Sensor $\boldsymbol{R}_{\mathbf{3}}$ & Sensor $\boldsymbol{R}_{\mathbf{4}}$ \\
\hline $\begin{array}{c}\text { Mean of the } \\
\text { empirical values } \\
\Delta R_{\text {i_avg }}[\Omega]\end{array}$ & 0.883 & 0.891 & 0.856 & 0.872 \\
\hline Linear model & $\Delta \hat{R}_{1}=a_{1} F$ & $\Delta \hat{R}_{2}=a_{2} F$ & $\Delta \hat{R}_{3}=a_{3} F$ & $\Delta \hat{R}_{4}=a_{4} F$ \\
\hline Straight-line slope $a_{i}$ & 0.01775 & 0.01786 & 0.01721 & 0.01765 \\
\hline $\begin{array}{c}\text { The standard error of } \\
a_{i} \text { coefficient }\end{array}$ & 0.00011 & 0.00010 & 0.00013 & 0.00017 \\
\hline $\begin{array}{c}\text { Coefficient of } \\
\text { determination } R^{2}\end{array}$ & 0.9996 & 0.9997 & 0.9993 & 0.9990 \\
\hline $\begin{array}{c}\text { Standard error of the } \\
\text { regression } s_{\mathrm{e}}\end{array}$ & 0.02172 & 0.02018 & 0.02723 & 0.03415 \\
\hline $\begin{array}{c}\text { The relative standard } \\
\text { error of assessment } \\
\text { model } \\
S_{e}\end{array} 100 \%$ & $2.46 \%$ & $2.26 \%$ & $3.18 \%$ & $3.92 \%$ \\
\hline \begin{tabular}{c}
$S_{\text {ew }}=\frac{\Delta R_{i} \text { avg }}{\Delta R_{\text {a }}} \%$ \\
\hline
\end{tabular} & & & \\
\hline
\end{tabular}

TABLE V. THEORETICAL MODELS FOR THE TESTED RECONFIGURABLE CIRCUIT, DESCRIBING RESISTANCE INCREASES OF THE SENSORS IN THE FORCE FUNCTION AND THEIR PARAMETERS.

\begin{tabular}{|c|c|c|c|c|}
\hline & Sensor $R_{1}$ & Sensor $R_{2}$ & Sensor $R_{3}$ & Sensor $R_{4}$ \\
\hline $\begin{array}{c}\text { Mean of the } \\
\text { empirical values } \\
\Delta R_{i \_ \text {avg }}[\Omega]\end{array}$ & 0.969 & 0.948 & 0.951 & 0.945 \\
\hline Linear model & $\Delta \hat{R}_{1}=a_{1} F$ & $\Delta \hat{R}_{2}=a_{2} F$ & $\Delta \hat{R}_{3}=a_{3} F$ & $\Delta \hat{R}_{4}=a_{4} F$ \\
\hline Straight-line slope $a_{i}$ & 0.01923 & 0.01892 & 0.01872 & 0.01910 \\
\hline $\begin{array}{c}\text { The standard error of } \\
a_{i} \text { coefficient }\end{array}$ & 0.00027 & 0.00021 & 0.00025 & 0.00030 \\
\hline $\begin{array}{c}\text { Coefficient of } \\
\text { determination } R^{2}\end{array}$ & 0.9981 & 0.9988 & 0.9982 & 0.9975 \\
\hline $\begin{array}{l}\text { Standard error of the } \\
\text { regression } s_{\mathrm{e}}\end{array}$ & 0.05226 & 0.04134 & 0.04850 & 0.05919 \\
\hline 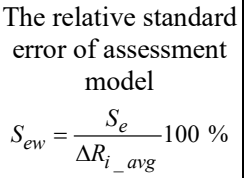 & $5.39 \%$ & $4.36 \%$ & $5.10 \%$ & $6.26 \%$ \\
\hline
\end{tabular}

The following linear models, describing dependences between the resistance increase of the sensors and the $F$ force, were assumed

$$
\Delta \hat{R}_{i}=a_{i} F
$$

Regression lines were determined by the classic least squares method. The differences (remainders) between empirical $\Delta R_{i}$ and theoretical $\Delta \hat{R}_{i}$ values equal

$$
\Delta r_{i}=\Delta R_{i}-\Delta \hat{R}_{i}
$$

The values are presented in Fig. 7 and Fig. 8. Standard error of the regression (standard deviation of the residuals) is described by the equation

$$
S_{e}=\sqrt{\frac{\sum_{i=1}^{L}\left(\Delta r_{i}\right)^{2}}{L-K}} .
$$

where $L$ - number of observation $(L=10), K$ - number of estimated parameters $(K=1)$ [12].

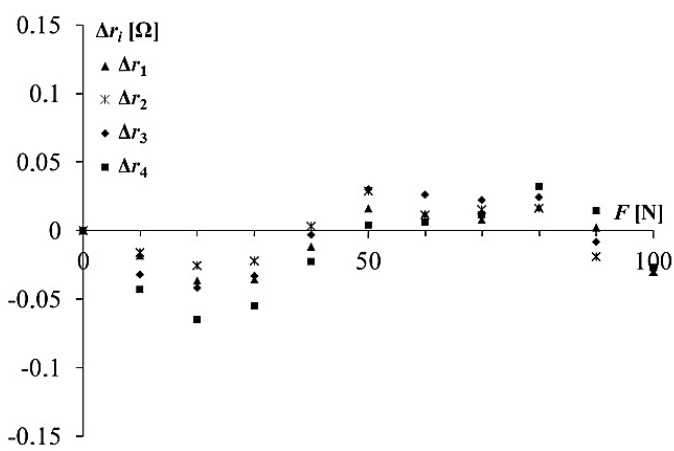

Fig. 7. Differences (remainders) $\Delta r_{i}$ between empirical $\Delta R_{i}$ and theoretical $\Delta \hat{R}_{i}$ values measured by an NI 9237 card.

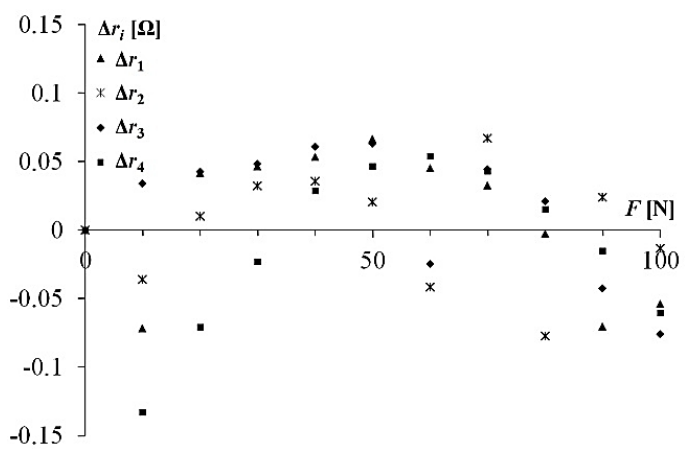

Fig. 8. Differences between $\Delta r_{i}$ between empirical $\Delta R_{i}$ and theoretical $\Delta \hat{R}_{i}$ values measured by a reconfigurable $2 \mathrm{~J}+2 \mathrm{R}+4 \mathrm{~K}$ circuit.

Table IV and Table V present the values of straight line slopes and standard errors of the regression $s_{e}$ for the frames of reference and the tested ones.

Relative standard errors of models evaluation (in the last line of Table IV and Table V) inform about the average difference between empirical and theoretical values determined on the basis of the linear models. They are situated within the range of $2.26 \%$ to $3.92 \%$ (the referential frame) and $4.36 \%$ to $6.26 \%$ (the tested circuit).

Additionally, the differences of the measured resistance increases were calculated. They were compared with the maximum measured value (by the NI 9237 bridge). In order to calculate the error (11), the average value of resistance increases of all four sensors $\Delta R_{\text {max_avg }}$ measured at the maximum force $F_{\max }=100 \mathrm{~N}(1.736 \Omega)$ was assumed

$$
\left|\delta_{R i}\right|=\frac{\left|\Delta R_{i}^{(2 \mathrm{~J}+2 \mathrm{R}+4 \mathrm{~K})}-\Delta R_{i}^{(\mathrm{NI} 9237)}\right|}{\Delta R_{\text {max_avg }}^{(\mathrm{NI} 9237)}} 100 \% .
$$

The values of the relative differences modules of the resistance increases, calculated in this manner, are collected in Table VI. 
TABLE VI. RELATIVE DIFFERENCES MODULE OF THE RESULTS OF THE RESISTANCE INCREASES MEASUREMENTS FOR $\Delta \mathrm{R}_{\mathrm{I}}$ SENSORS IN THE NI 9237 AND THE $2 \mathrm{~J}+2 \mathrm{R}+4 \mathrm{~K}$.

\begin{tabular}{|c|c|c|c|c|}
\hline & Sensor $\boldsymbol{R}_{\mathbf{1}}$ & Sensor $\boldsymbol{R}_{\mathbf{2}}$ & Sensor $\boldsymbol{R}_{\mathbf{3}}$ & Sensor $\boldsymbol{R}_{\mathbf{4}}$ \\
\hline$F[\mathrm{~N}]$ & $\left|\delta_{R 1}\right|[\%]$ & $\left|\delta_{R 2}\right|[\%]$ & $\left|\delta_{R 3}\right|[\%]$ & $\left|\delta_{R 4}\right|[\%]$ \\
\hline 0 & 0.00 & 0.00 & 0.00 & 0.00 \\
\hline 10 & 2.24 & 0.57 & 4.63 & 4.34 \\
\hline 20 & 6.11 & 3.21 & 6.55 & 1.27 \\
\hline 30 & 7.15 & 4.85 & 7.25 & 4.23 \\
\hline 40 & 7.00 & 4.19 & 7.10 & 6.15 \\
\hline 50 & 6.96 & 2.42 & 6.21 & 6.44 \\
\hline 60 & 6.78 & 0.48 & 2.31 & 7.54 \\
\hline 70 & 7.11 & 7.05 & 7.36 & 7.43 \\
\hline 80 & 5.41 & 0.67 & 6.75 & 5.45 \\
\hline 90 & 3.18 & 7.69 & 5.83 & 5.54 \\
\hline 100 & 6.79 & 6.76 & 5.98 & 6.11 \\
\hline
\end{tabular}

The obtained results take the values within the range of $0 \%$ to $7.69 \%$.

Furthermore, the relative differences of the straight-line slope $a_{i}$ of sensors characteristics both in the NI 9237 and the $2 \mathrm{~J}+2 \mathrm{R}+4 \mathrm{~K}$ were calculated. Values $a_{i}$ of linear models (8), calculated on the basis of measurement results obtained by the NI 9237 strain gauge bridge (calibrated in the temperature of $23{ }^{\circ} \mathrm{C}$ ), were assumed as reference. They are almost identical. The comparison of $a_{i}$ values in Table IV and Table $\mathrm{V}$ and the analysis of the equation of the relative difference in value of the straight-line slopes result in Table VII

$$
\left|\delta_{a i}\right|=\frac{\left|a_{i}^{(2 \mathrm{~J}+2 \mathrm{R}+4 \mathrm{~K})}-a_{i}^{(\mathrm{NI} 9237)}\right|}{a_{i}^{(\mathrm{NI} 9237)}} 100 \% .
$$

TABLE VII. RELATIVE DIFFERENCES OF STRAIGHT-LINE SLOPES OF SENSORS CHARACTERISTICS IN THE NI 9237 AND THE $2 \mathrm{~J}+2 \mathrm{R}+4 \mathrm{~K}$.

\begin{tabular}{|c|c|c|c|c|c|}
\hline & $\begin{array}{c}\text { Sensor } \\
\boldsymbol{R}_{\mathbf{1}}\end{array}$ & $\begin{array}{c}\text { Sensor } \\
\boldsymbol{R}_{\mathbf{2}}\end{array}$ & $\begin{array}{c}\text { Sensor } \\
\boldsymbol{R}_{\mathbf{3}}\end{array}$ & $\begin{array}{c}\text { Sensor } \\
\boldsymbol{R}_{\mathbf{4}}\end{array}$ & $\begin{array}{c}\text { Mean } \\
\text { value }\end{array}$ \\
\hline $\begin{array}{c}\text { Relative } \\
\text { difference }\left|\delta_{a i}\right|\end{array}$ & $8.31 \%$ & $5.93 \%$ & $8.73 \%$ & $8.23 \%$ & $7.80 \%$ \\
\hline
\end{tabular}

\section{SUMMARY}

The results obtained by the self-constructed circuit had broader dispersion of the $\Delta r_{i}$ difference values between the empirical $\Delta R_{i}$ and the theoretical $\Delta \hat{R}_{i}$ values in comparison with the results obtained by the NI 9237 bridge (Fig. 7 and Fig. 8). Relative standard errors of the models evaluation equalled $4.36 \%$ to $6.26 \%$ in the reconfigurable circuit (the last line in Table V). The same errors for the NI 9237 bridge equalled $2.26 \%$ do $3.92 \%$ (the last line in Table IV). Similarly, standard error values of the straight-line slopes of the sensors were greater for the built prototype than for the commercial product (Table IV and Table V).

However, the straight-line slopes of the sensors cooperating with the NI 9237 and with the reconfigurable circuit differed averagely of about $7.80 \%$ (Table VII). On the other hand, relative differences modules of the measurement results for resistance increases $\left|\delta_{R i}\right|$ were not greater than $7.69 \%$ between the tested circuits (Table VI). Such values of deviations from the assumed model seem to be acceptable.

\section{CONCLUSIONS}

A reconfigurable circuit with four switching keys is so universal that it can be used to measure potentials in 4 nodes: A, B, C and D, in selected cycles and calculate combinations of increases of four resistances. With the use of cycles 10,20,30,40, 1 and 2 and some arithmetic operations on the dependences given in Table III, it is possible to obtain equations for various combinations of increases. For the circuit with four switching keys, the increases were determined as $\Delta R_{i}=\varepsilon_{i} R_{i 0}$ for $i=1,2,3,4$. This means greater measuring possibilities of the keying circuit, as the zero correction is realized in the same circuit (with the use of 10, 20,30, and 40 cycles) and cooperation of the circuit with the sensors of various initial resistances is possible.

The reconfigurable circuit was tested in static measurements. During further research, it is planned to conduct dynamic tests and to apply the circuit in a stabilographic platform [13].

\section{REFERENCES}

[1] B. Maundy, S. J. G. Gift, "Strain gauge amplifier circuits", IEEE Trans. Instrumentation and Measurement, vol. 62, no. 4, pp. 693-700, 2013. [Online]. Available: http://dx.doi.org/10.1109/TIM.2013. 2246904

[2] V. V. Gureyev, A. A L'vov, V. A. Pylskiy, "Improvement of the current loop circuit for AC and DC applications based on digital signal processing", Instrumentation and Measurement Technology Conf. (IMTC 2006), Sorrento, Italy, 2006, pp. 1257-1261. [Online]. Available: http://dx.doi.org/10.1109/IMTC.2006.328489

[3] R. Kvedaras, V. Kvedaras, "Strain measurements and monitoring of constructions", Elektronika ir Elektrotechnika, vol. 81, no. 1, pp. 65$68,2008$.

[4] W. Walendziuk, A. Idzkowski, Z. Machacek, Z. Slanina, "Evaluation of Pt100 sensor deflection effect during strain measurements", Elektronika ir Elektrotechnika, vol. 21, no. 4, pp. 23-26, 2015. [Online]. Available: http://dx.doi.org/10.5755/j01.eee.21.4.12776

[5] National Instruments, NI USB-9237 user guide and specifications, [Online]. Available: http://www.ni.com/pdf/manuals/372306b.pdf

[6] L. Cvitas, Z. Hocenski, "Increasing accuracy of temperature measurement based on adaptive algorithm for microcontroller transmitter", Tehnicki Vjesnik-Technical Gazette, vol. 17, no. 4, pp. 445-452, 2010.

[7] National Instruments, DAQ M Series NI USB-621x user manual. [Online]. Available: http://www.ni.com/pdf/manuals/371931f.pdf

[8] A. Idzkowski, P. Swietochowski, W. Walendziuk, Z. L. Warsza, "Unconventional double $\mathrm{R} / \mathrm{U}$ converter for measurement of two quantities by a single differential sensor", Advances in Intelligent Systems and Computing, vol. 352, pp. 83-90, 2015. [Online]. Available: http://dx.doi.org/10.1007/978-3-319-15835-8_10

[9] B. Yousefzadeh, U. Sonmez, N. Mehta, J. Borremans, M. A. P. Pertijs, K. A. A. Makinwa, "A generic read-out circuit for resistive transducers", 6th IEEE Int. Workshop on Advances in Sensors and Interfaces (IWASI 2015), IEEE Conf. Publications, 2015, pp. 122125, [Online]. Available: http://dx.doi.org/10.1109/IWASI.2015. 7184929

[10] ZEPWN, CL363 force meter user manual. [Online]. Available: http://cms.zepwn.com.pl/zepwn/_media/products/pdf-pl/karta_cl363_ 2010_02_01.pdf

[11] ZEPWN, weight load cell product datasheet. [Online]. Available: http://cms.zepwn.com.pl/zepwn/_media/products/pdf-en/card_ cl17mp.pdf

[12] Evaluation of measurement data - Guide to the expression of uncertainty in measurement, JCGM (Joint Committee of Guides in Metrology), 2008.

[13] W. Walendziuk, "Measurement uncertainty analysis of the strain gauge based stabilographic platform", Acta mechanica et automatica, vol. 8 , no. 2 , pp. $74-78,2014$. 